\title{
Effectiveness of clove oil as an Anesthetic on Mozambique tilapia (Oreochromis mossambicus)
}

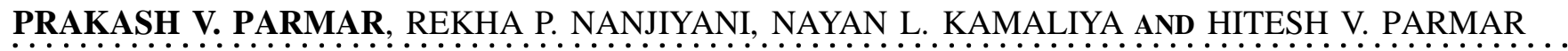

Author for Corresponding -

\section{PRAKASH V. PARMAR}

Department of Aquaculture, College of Fisheries Science, Junagadh Agricultural University, VERAVAL (GUJARAT) INDIA

Email : pvparmar@gmail.com

See end of the article for

Coopted authors'
ABSTRACT...... Anesthesia in aquaculture is generally used during sampling, weighing, disease diagnosis and transportation. Total 99 fish (mean length $6.55 \mathrm{~cm} \pm 0.04$; mean weight $3.64 \mathrm{~g} \pm 0.05$ ) were used for this experiment. This experiment was carried out in triplicate using ten different concentration of clove oil $(10,20,30,40,50,60,70,80,90,100 \mathrm{mg} / \mathrm{l})$ along with control (without clove oil). For the experiment, 1 litre tanks were used as induction tank and 10 litre tanks were used as recovery tank. Clove oil is not soluble in water so stock solution was prepared using absolute ethanol in the ratio of 1:10 before experiment and directly added to induction tank and induction time was measured. The fish werethen transferred to recovery tank and three different stages of recovery were measured. Clove oil concentration $10 \mathrm{mg} / \mathrm{l} \mathrm{did}$ not produce any stage of anesthesia while $20 \mathrm{mg} / \mathrm{l}$ produced only two stages of induction and recovery. As the concentration of clove oil increased from $30 \mathrm{mg} / \mathrm{l}$ to $100 \mathrm{mg} / \mathrm{l}$, time of induction decreased and time of recovery increased. $100 \mathrm{mg} / \mathrm{l}$ was found to be an ideal concentration as it produced induction in less than $3 \mathrm{~min}$. The result of this experiment suggested that clove oil can be used as an effective anesthetic on tilapia which produced minimum stress without mortality.

KEY WORDS....... Aquaculture, Anesthetic, Clove oil, Oreochromis mossambicus, Induction time, Recovery time

HOW TO CITE THIS ARTICLE - Parmar, Prakash V., Nanjiyani, Rekha P., Kamaliya, Nayan L. and Parmar, Hitesh V. (2017). Effectiveness of clove oil as an Anesthetic on Mozambique tilapia (Oreochromis mossambicus). Asian J. Animal Sci., 12(2): 149-153. DOI : 10.15740/HAS/TAJAS/12.2/149-153.

ARTICLE CHRONICLE - Received : 12.10.2017; Revised : 12.11.2017; Accepted : 25.11.2017 